\title{
Preparation of manganese-doped $\mathrm{ZnO}$ thin films and their characterization
}

\author{
S MONDAL, S R BHATTACHARYYA ${ }^{\dagger}$ and P MITRA* \\ Department of Physics, University of Burdwan, Golapbag, Burdwan 713 104, India \\ ${ }^{\dagger}$ Surface Physics Division, Saha Institute of Nuclear Physics, Kolkata 700 064, India
}

MS received 8 January 2012; revised 21 March 2012

\begin{abstract}
In this study, pure and manganese-doped zinc oxide (Mn:ZnO) thin films were deposited on quartz substrate following successive ion layer adsorption and reaction (SILAR) technique. The film growth rate was found to increase linearly with number of dipping cycle. Characterization techniques of XRD, SEM with EDX and UVvisible spectra measurement were done to investigate the effect of Mn doping on the structural and optical properties of $\mathrm{Mn}: \mathrm{ZnO}$ thin films. Structural characterization by X-ray diffraction reveals that polycrystalline nature of the films increases with increasing manganese incorporation. Particle size evaluated using X-ray line broadening analysis shows decreasing trend with increasing manganese impurification. The average particle size for pure $\mathrm{ZnO}$ is $29.71 \mathrm{~nm}$ and it reduces to $23.76 \mathrm{~nm}$ for $5 \% \mathrm{Mn}$-doped $\mathrm{ZnO}$. The strong preferred $c$-axis orientation is lost due to manganese (Mn) doping. The degree of polycrystallinity increases and the average microstrain in the films decreases with increasing Mn incorporation. Incorporation of Mn was confirmed from elemental analysis using EDX. As the Mn doping concentration increases the optical bandgap of the films decreases for the range of Mn doping reported here. The value of fundamental absorption edge is $3.22 \mathrm{eV}$ for pure $\mathrm{ZnO}$ and it decreases to 3.06 eV for $5 \% \mathrm{Mn}: \mathrm{ZnO}$.
\end{abstract}

Keywords. SILAR; Mn:ZnO thin film; X-ray line broadening; SEM; optical bandgap.

\section{Introduction}

Zinc oxide is a II-IV semiconductor compound and has a large direct bandgap around $3 \cdot 2-3 \cdot 37 \mathrm{eV}$ at $300 \mathrm{~K}$ with a high exciton binding energy of $60 \mathrm{meV}$ (Nirmala and Anukaliani 2010). ZnO thin films are important materials due to their unique properties such as piezoelectricity, chemical stability, biocompatibility, high catalytic activity in different gas ambient, high optical transparency in the visible region and high voltage-current nonlinearity etc. (Look 2001; Keis et al 2002; Maiti et al 2007). Accordingly it has an immense potential in different applications in photo-thermal conversion systems, heat mirrors, hetero-junction solar cells, transparent electrodes, blue/UV-light emitter device, solid state sensor, transducer, etc. (Wang et al 1995; Natsume 2000; Negami et al 2001). Pure zinc oxide thin films have certain limitations in their application. In order to widen the potential areas where $\mathrm{ZnO}$ thin films can be applied, dopant ions have to be incorporated into them to obtain certain desired properties like wider or narrower bandgap, higher optical absorbance, lower or higher melting point, ferromagnetism, etc. Mn-doped $\mathrm{ZnO}$ has the potential to be a multifunctional material with coexisting magnetic, semi-conducting and optical properties (Mandal and Nath 2006). It is regarded

\footnotetext{
*Author for correspondence (mitrapartha1@ rediffmail.com)
}

as promising material for spintronic applications as it shows room temperature ferromagnetism (Singhal et al 2009). Thus $\mathrm{Mn}$-doped $\mathrm{ZnO}$ has been synthesized primarily to study its ferromagnetic behaviour (Sharma et al 2003; Kundaliya et al 2004). Due to its unique magneto-optical, magnetoelectrical and magneto-transport properties, it is also considered as a dilute magnetic semiconductor (DMS) material. Various physical and chemical techniques that has been used to deposit $\mathrm{Mn}: \mathrm{ZnO}$ thin films and nanofilms includes rf or d.c. sputtering, pulsed-laser deposition (PLD), ion plating, chemical vapour deposition (CVD), thermal evaporation, spray pyrolysis, molecular beam epitaxy (MBE), etc. (Nirmala and Anukaliani 2010). Chemical techniques are relatively simpler and cost effective.

In the present work, an attempt has been made to synthesize $\mathrm{Mn}$-doped $\mathrm{ZnO}$ thin films by a chemical dipping technique. In this technique, a glass substrate is dipped alternately into beakers containing aqueous solutions or distilled water for the reaction to take place at the substrate surface. The substrate can be introduced into various reactants for a specific length of time depending on the nature and kinetics of the reaction. The immersion-reaction cycle can be repeated for any number of times, limited only by the inherent problems associated with the deposition technique and the substrate-thin film interface. The technique is called SILAR (successive ion layer adsorption and reaction) since it involves adsorption of a layer of complex ion on the substrate followed by the reaction of the adsorbed ion layer. 
Thus SILAR is one such process which is based on successive irreversible acts of adsorption of cations and then anions. Since the synthesis can be carried out under 'mild conditions' and at lower processing temperatures, implantation of metal ions at low temperatures may be particularly suitable by this method. Lower processing temperature also prevents the films from considerable loss of their intrinsic electrical and optical properties as well. The SILAR deposition from aqueous solutions is a very promising method because of its simplicity and economy. The technique is, however, a relatively less used and studied one and there are no reports of synthesis of $\mathrm{Mn}: \mathrm{ZnO}$ thin films by SILAR. The advantages of this method are its simplicity of working principle and low cost of apparatus. Earlier we have reported the synthesis of $\mathrm{ZnO}$, aluminum and cadmium-doped $\mathrm{ZnO}$ (Mitra and Khan 2006; Mondal et al 2008; Mondal and Mitra 2012) thin films by SILAR. The primary aim of the present work was to explore the possibility of utilizing SILAR to impurify $\mathrm{ZnO}$ thin film with Mn.

\section{Experimental}

Deposition of pure $\mathrm{ZnO}$ film was carried out from $0.1 \mathrm{M}$ zinc chloride $\left(\mathrm{ZnCl}_{2}\right)$ solution kept at room temperature and $0.075 \mathrm{M}$ sodium hydroxide $(\mathrm{NaOH})$ solution maintained at $70^{\circ} \mathrm{C}$. Commercially available quartz substrate was used for film deposition. The substrate was cleaned before deposition, by etching in $1 \%$ hydrofluoric acid (HF) for $24 \mathrm{~h}$ followed by ultrasonic cleaning in equivolume acetone and alcohol and thorough rinsing in deionized water. The cleaned substrate was alternatively dipped in zinc chloride solution and hot $\mathrm{NaOH}$ solution. One complete set of dipping cycle involves dipping in zinc chloride bath for $2 \mathrm{~s}$ and dipping in sodium hydroxide bath for $2 \mathrm{~s}$. For Mn doping, manganese (II) chloride $\left(\mathrm{MnCl}_{2} \cdot 4 \mathrm{H}_{2} \mathrm{O}\right.$, Merck, mol. wt. 197.9) dissolved in zinc chloride solution was used as a source of $\mathrm{Mn}^{2+}$ dopant ions. The manganese concentration was varied up to $5 \%$ in the zinc chloride solution for the preparation of doped films. Film thickness was measured using gravimetric weight difference method (Kale et al 2007; Mondal and Mitra 2012).

The X-ray diffraction profiles of the pure and doped samples were recorded using $\mathrm{Ni}$-filtered $\mathrm{CuK}_{\alpha}$ radiation from a highly stabilized and automated Philips X-ray generator (PW 1830) operated at $40 \mathrm{kV}$ and $20 \mathrm{~mA}$. The experimental peak positions were compared with the standard JCPDS files and the Miller indices were indexed to the peaks. Scanning electron microscopy (SEM, Model S530, Hitachi, Japan) was used to study the surface morphology and to illustrate the formation of crystallites on the film surface. Energy dispersive X-ray analysis (EDX) was employed for the compositional analysis. UV-Vis spectrophotometer measurements were performed by using a spectrophotometer (Shimadzu, UV-1800) at room temperature. The spectra were recorded by using a similar quartz substrate as a reference and hence the absorption due to the film only was obtained. The bandgap of the films has been evaluated from the absorption edge of the spectrum.

\section{Results and discussion}

\subsection{Film deposition and thickness measurement}

The zinc chloride bath, used for deposition was prepared by adding zinc chloride in deionized water. $6.814 \mathrm{gm}$ zinc chloride $\left(\mathrm{ZnCl}_{2}\right.$, Merck, mol. wt. 136.28) was added in $500 \mathrm{cc}$ deionized water to have a bath solution of $0.1 \mathrm{M} \mathrm{ZnCl}$. One of the problems with zinc chloride solution is that complete dissolution of the solute does not occur and precipitate appears on standing. Addition of three drops of acetic acid ( $\sim 0.3 \mathrm{cc}$ by volume) gives a clear transparent solution. The $\mathrm{pH}$ of the transparent solution was 4.70. $\mathrm{pH}$ measurement was carried out in a Systronics pH meter (Model 335). $0.075 \mathrm{M}$ sodium hydroxide solution was prepared by dissolving $\mathrm{NaOH}$ pellets (Merck, mol. wt. 40) in $500 \mathrm{cc}$ deionized water. The $\mathrm{pH}$ of the sodium hydroxide bath was 11.10. The concentrations of the reacting baths used were found to be optimum for synthesis of good quality adherent film. For concentrations more than $0.125 \mathrm{M}$ for zinc chloride bath and/or for concentrations more than $0.075 \mathrm{M}$ for sodium hydroxide bath, particulate absorption took place on the film surface making the growth process nonuniform and resulting in poor quality films. For still higher concentrations of either bath, film detachment from the substrate surface takes place and no layer could be deposited. The film thickness $(t)$ was built up by increasing the number of dipping cycle. The deposited films were subsequently annealed in air at $350^{\circ} \mathrm{C}$ for $2 \mathrm{~h}$. Figure 1 shows the dependence of film thickness on the number of dipping cycles $(N)$. The film thickness was determined gravimetrically by measuring the change in weight of the substrate due to film deposition,

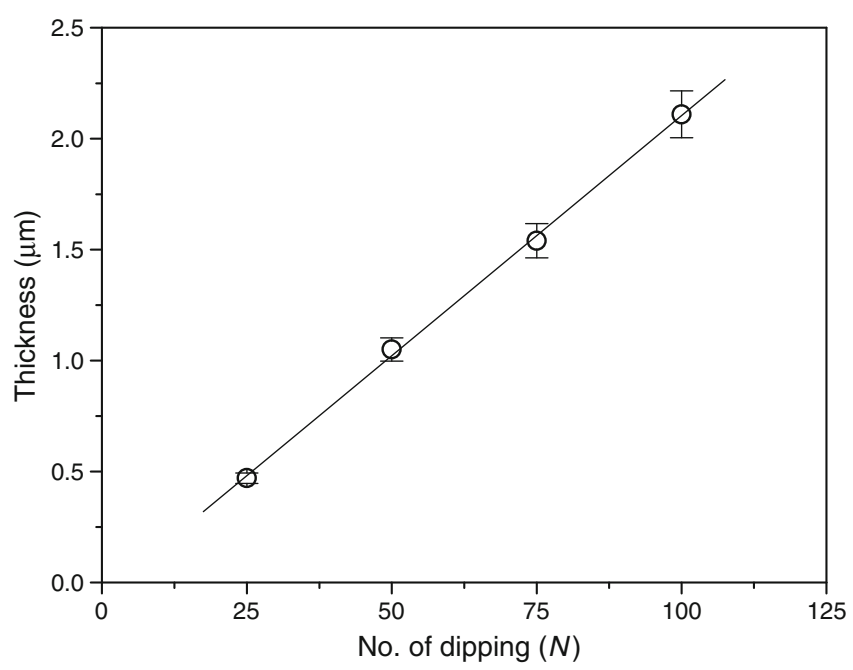

Figure 1. Dependence of film thickness on number of dipping cycles. 
the area of deposition and using the known density of $\mathrm{ZnO}$ $\left(5.6 \mathrm{gm} / \mathrm{cm}^{3}\right)$. Thus, if $W_{1}$ and $W_{2}$ are the weights of the substrate before and after film deposition in $\mathrm{g}, A$ is the area of film deposition in $\mathrm{cm}^{2}$ and $\rho$ is the theoretical density of $\mathrm{ZnO}$, then the film thickness is evaluated as:

$$
d=\frac{\left(W_{2}-W_{1}\right)}{A \rho} \times 10^{-4} \mu \mathrm{m} .
$$

It is seen from figure 1 that the film thickness follows a linear growth law with number of dipping cycle and the growth rate was found to be $0.021 \mu \mathrm{m} /$ dipping for pure $\mathrm{ZnO}$ film measured gravimetrically. There is an overall variation of $\pm 5 \%$ in the film thickness data (shown as error bars against each data point of figure 1). This reflects a small variability in the deposition process arising probably from small experimental scatter in deposition parameters (e.g. bath concentration, bath temperature, etc.) as well as due to the nonuniformity of the substrate handling procedure as the deposition is carried out manually.

The growth rate was found to decrease with Mn incorporation. For 50 dipping, the film thickness for pure $\mathrm{ZnO}$ was $1.05 \mu \mathrm{m}$. The corresponding thickness for $2 \% \mathrm{Mn}: \mathrm{ZnO}$ film was $0.94 \mu \mathrm{m}$ and for $5 \% \mathrm{Mn}: \mathrm{ZnO}$, the thickness was $0.82 \mu \mathrm{m}$. Thus the growth rate decreases with increasing Mn incorporation. It was $0.021 \mu \mathrm{m} /$ dipping for pure $\mathrm{ZnO}$. It reduces to $0.0188 \mu \mathrm{m} /$ dipping and $0.0164 \mu \mathrm{m} /$ dipping for 2 and 5\% $\mathrm{Mn}: \mathrm{ZnO}$, respectively. The $\mathrm{ZnO}$ film was white in appearance and Mn-doped films were slightly brownish with a good adherence to the substrate.

The film thickness was also checked against crosssectional SEM. Some portion of the substrate was acid etched to remove film from that area in order to create a step for thickness measurement. Figure 2 shows cross-sectional SEM micrograph of undoped $\mathrm{ZnO}$ film of thickness $2.1 \mu \mathrm{m}$ measured gravimetrically (obtained by 100 dipping). An

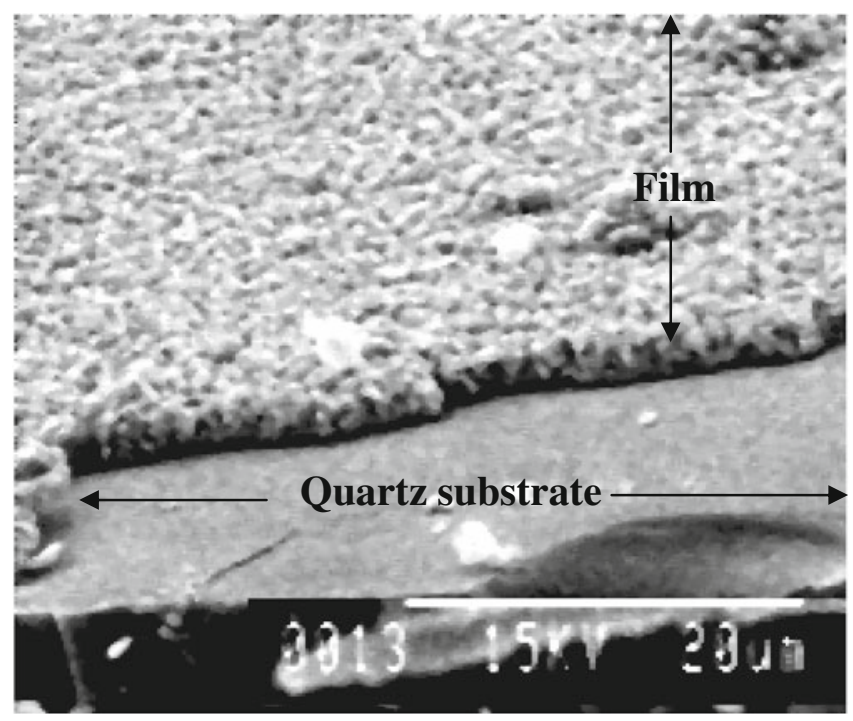

Figure 2. Cross-sectional SEM of undoped $\mathrm{ZnO}$ film. average thickness of $2.56 \mu \mathrm{m}$ was obtained from SEM micrograph. The value was an average of several measurements on different portions.

The gravimetric method does not take account of porosity in the films. As the films are porous in nature, the actual film density is always lower than the theoretical density. So the film thicknesses estimated using the theoretical density value is the minimum value and is always less than the actual thickness. The actual thickness determined from cross-sectional SEM is $22 \%$ higher than the gravimetric value $(2.56 \mu \mathrm{m}$ measured by TEM as opposed to $2.1 \mu \mathrm{m}$ measured gravimetrically). This indicates a porosity of $\sim 22 \%$ in the deposited films.

\subsection{Structural characterization}

The X-ray diffraction patterns of undoped $\mathrm{ZnO}$ and $\mathrm{Mn}$ doped $\mathrm{ZnO}$ films are shown in figure 3. The diffractions pattern for undoped $\mathrm{ZnO}$ is shown in figure 3(a). Figures 3(b) and (c) show the diffractograms for 2 and 5\% $\mathrm{Mn}: \mathrm{ZnO}$ films, respectively. The films were heat treated at $350{ }^{\circ} \mathrm{C}$ for $2 \mathrm{~h}$, prior to structural characterization. The materials were scanned in the range $25-65^{\circ}$. The $2 \theta$ variation was employed with a $0 \cdot 05^{\circ}$ step and a time step of $1 \mathrm{~s}$. Intensity in arbitrary units is plotted against $2 \theta$ in figure 1 . It is seen from figure 3(a) that peaks appear at $31 \cdot 708,34 \cdot 397,36 \cdot 183,47 \cdot 516$, 56.551 and $62.88^{\circ}$. The diffractogram of the sample reveals that all the peaks are in good agreement with the joint committee on powder diffraction standard (JCPDS) data belonging to hexagonal $\mathrm{ZnO}$ structure (Card No. 36-1451). The corresponding reflecting planes are (100), (002), (101), (102),

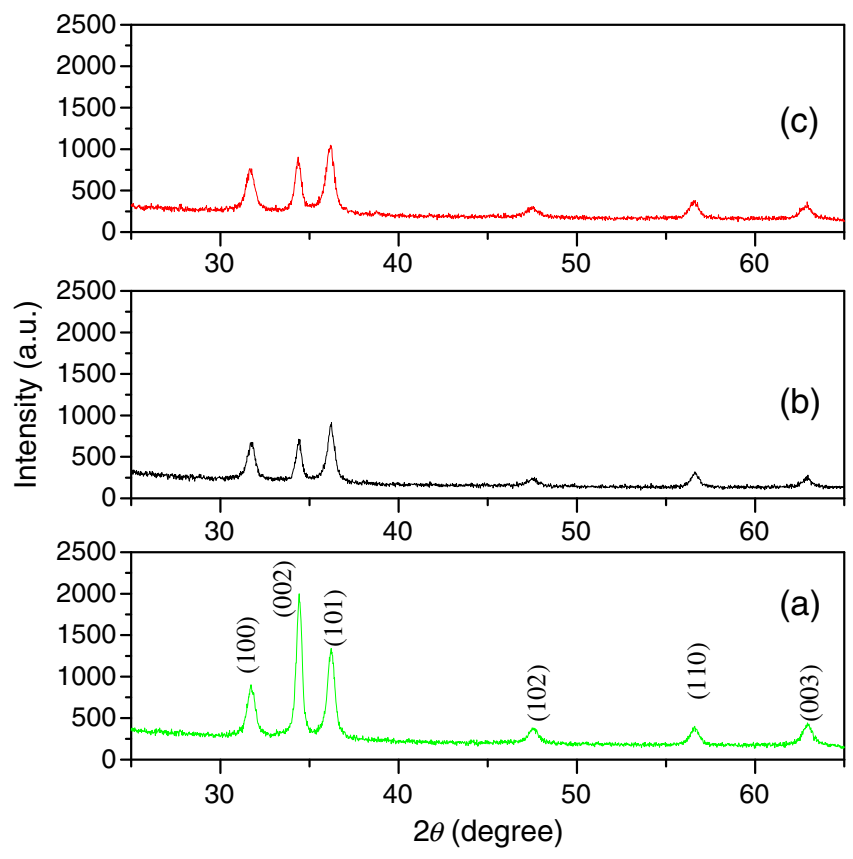

Figure 3. X-ray diffraction pattern of (a) $\mathrm{ZnO}$, (b) $2 \% \mathrm{Mn}: \mathrm{ZnO}$ and (c) $5 \% \mathrm{Mn}: \mathrm{ZnO}$. 
(110) and (103), respectively. The (002) peak appears with maximum intensity at $34.397^{\circ}$. Apart from $\mathrm{ZnO}$ characteristic peaks, no extra peaks due to manganese clusters, zinc or their complex oxides could be detected. This observation suggests that the films are single phase and $\mathrm{Mn}$ ion might have substituted $\mathrm{Zn}$ site without changing the hexagonal structure.

It is evident from figure 3(a) that undoped $\mathrm{ZnO}$ film have a polycrystalline structure with preferred orientation mostly along the (002) diffraction plane. Compared to pure $\mathrm{ZnO}$ film, the intensity of (002) peak decreases for $\mathrm{Mn}: \mathrm{ZnO}$ films. This results in an increase of relative intensity of (101) peak w. r. t. (002) peak. The (101) peak appears with maximum intensity in $\mathrm{ZnO}$ powders with no preferred orientation (Mitra and Khan 2006). Thus crystalline nature of films was affected due to enhancement of dopant concentration, by which manganese impurities were included in the $\mathrm{ZnO}$ crystal. Such loss of preferred orientation and crystalline nature with $\mathrm{Mn}$ incorporation has been reported by Nirmala and Anukaliani (2010). Doping results in loss of preferred orientation along $c$-axis. Utilizing the X-ray diffraction data, the average particle size was estimated from Williamson-Hall equation (Ungar and Borbely 1996; Choudhury and Sarma 2009).

$$
\beta \cos \theta=\frac{k \lambda}{D}+4 \varepsilon \sin \theta,
$$

where $\lambda$ is the wavelength of radiation used $(1.542 \AA$ of $\mathrm{CuK}_{\alpha}$ radiation used), $k$ the Scherrer constant, $\beta$ the full width at half maximum (FWHM) intensity of the diffraction peak for which the particle size is to be calculated, $\theta$ the diffraction angle of the concerned diffraction peak, $D$ the crystallite dimension (or particle size) and $\varepsilon$ the microstrain. In general, the experimentally observed X-ray peak broadening $\left(\beta_{\mathrm{o}}\right)$ is a convolution of (i) instrumental broadening; $\left(\beta_{\mathrm{i}}\right)$, (ii) particle (crystallite) size broadening $\left(\beta_{\mathrm{D}}\right)$ and (iii) lattice strain broadening $\left(\beta_{\mathrm{S}}\right)$. The total broadening due to size and strain $(\beta)$ can be represented as $\beta=\beta_{\mathrm{D}}+\beta_{\mathrm{S}}$ and can be obtained from the experimentally observed broadening $\left(\beta_{\mathrm{o}}\right)$ using the equation (Klug and Alexander 1974; Patra et al 2011):

$$
\beta=\beta_{\mathrm{o}}-\beta_{\mathrm{i}} \text {. }
$$

Diffraction data from standard silicon ( $\mathrm{Si}$ ) powder was used to estimate the instrumental broadening (Sharma et al 2003; Patra et al 2011). The broadening (in FWHM) against $2 \theta$ obtained for standard silicon sample was plotted in a graph and was used as reference. The instrumental broadening at the observed peak positions for $\mathrm{ZnO}$ and $\mathrm{Mn}$-doped $\mathrm{ZnO}$ was evaluated from the graph.

$\mathrm{X}$-ray line broadening analysis to evaluate $\operatorname{FWHM}(\beta)$ was carried out using computer software (MARQ2) (Jumin and Wang 2001; Ghosh et al 2009). The software utilizes Marquardt least-squares procedure for minimizing the difference between the observed and simulated diffraction patterns. The peak shape and intensity of reflection is modeled with a

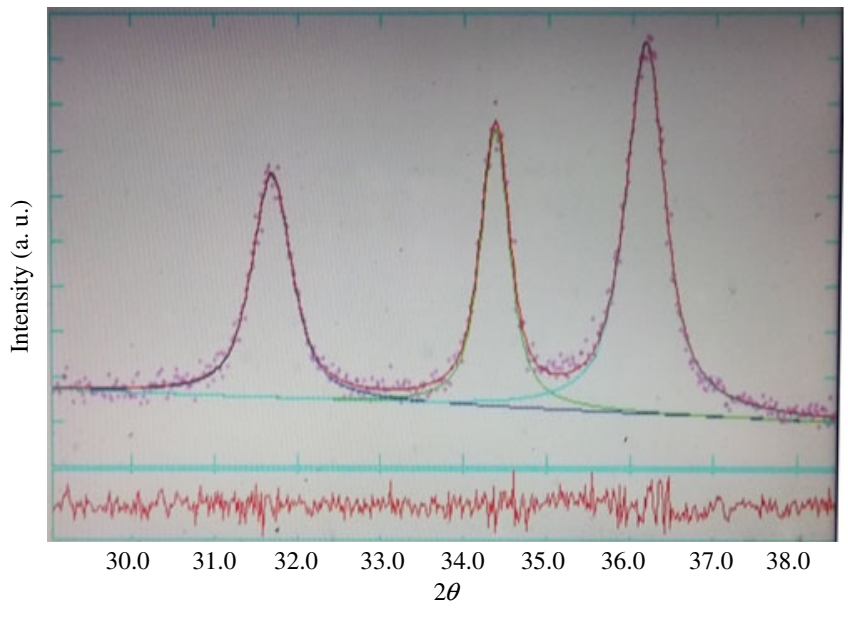

Figure 4. Observed (dotted) and simulated (continuous) X-ray diffraction patterns of $5 \% \mathrm{Mn}: \mathrm{ZnO}$.

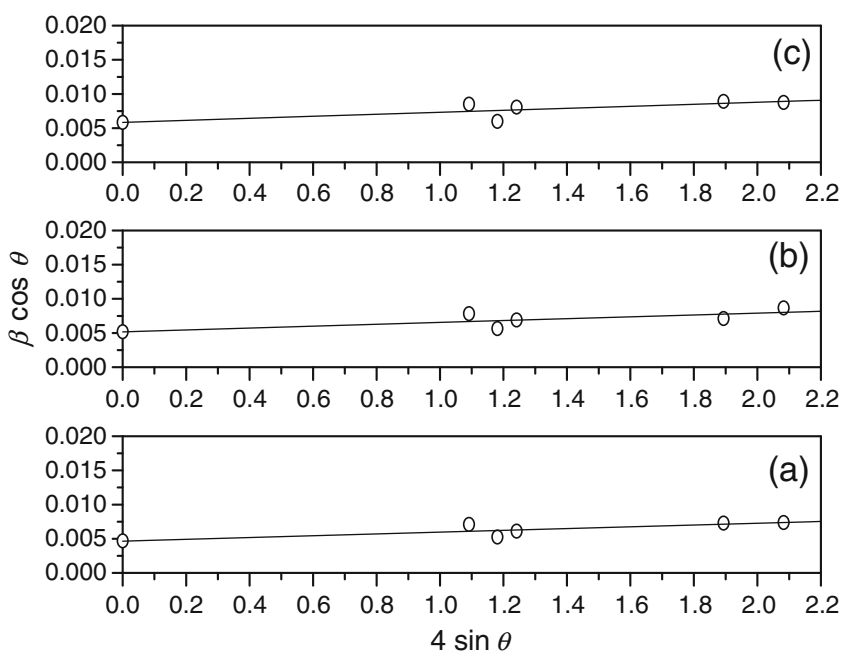

Figure 5. Williamson-Hall plots of (a) pure $\mathrm{ZnO}$, (b) $2 \%$ $\mathrm{Mn}: \mathrm{ZnO}$ and (c) $5 \% \mathrm{Mn}: \mathrm{ZnO}$ films.

pseudo-Voigt $(\mathrm{pV})$ analytical function, which is a combination of a Gaussian and a Lorentzian functions. The background intensity is subtracted by fitting the background with a suitable linear function. A typical plot of MARQ2 analysis for $5 \% \mathrm{Mn}: \mathrm{ZnO}$ sample is shown in figure 4 . The dotted curve represents the experimental intensity data $\left(I_{0}\right)$ while the continuous curve represents the calculated (simulated) intensity data $\left(I_{\mathrm{c}}\right)$. The difference plot $\left(I_{\mathrm{c}}-I_{\mathrm{o}}\right)$ is shown at the bottom of figure 4 .

From the values of $\beta_{\mathrm{o}}$ obtained using MARQ2 fitting and the corresponding values of instrumental broadening, $\beta_{\mathrm{i}}$, FWHM $\beta$ was calculated using (2). Figure 5 shows the plot of $\beta \cos \theta$ ordinate against $4 \sin \theta$ along abscissa (Williamson-Hall plots). The slope of the straight line plots represents average strain in the films whereas the inverse of intercept on $\beta \cos \theta$ axis gives the crystallite size $(D)$ 
according to (1). The particle size was evaluated using $k=$ $0 \cdot 9$, which corresponds to spherical crystallites and $\lambda=$ $1.5418 \AA$, the wavelength of $\mathrm{CuK}_{\alpha}$ radiation. The average value of particle size for pure $\mathrm{ZnO}$ is $29.71 \mathrm{~nm}$. It decreases to $26.79 \mathrm{~nm}$ for $2 \% \mathrm{Mn}: \mathrm{ZnO}$ and $23.76 \mathrm{~nm}$ for $5 \% \mathrm{Mn}: \mathrm{ZnO}$. The average microstrain in the films as determined from $\mathrm{W}-$ $\mathrm{H}$ plots is $0.0013,0.00137$ and 0.00146 , respectively for pure, $2 \% \mathrm{Mn}: \mathrm{ZnO}$ and 5\% $\mathrm{Mn}: \mathrm{ZnO}$ films, respectively. Thus the particle size decreases with increasing $\mathrm{Mn}$ incorporation and the strain increases. The decrease in average particle size with increasing $\mathrm{Mn}$ doping, i.e. hindrance of grain growth upon $\mathrm{Mn}$ incorporation has been reported by other workers (Luo et al 2005; Deka and Roy 2007; Senthilkumar et al 2008). The decrease in average particle size might be due to the development of strain in the films because of Mn incorporation. Such enhancement of average microstrain with $\mathrm{Mn}$ incorporation has been observed in the present work.

Figure 6 shows the HRSEM micrograph of pure $\mathrm{ZnO}$ film. HRSEM image shows structure consisting of many spherical shaped nanoparticles. The average particle size was found to be $\sim 31 \mathrm{~nm}$ which matches well with that obtained using Xray line broadening analysis. HRSEM study was undertaken in a FEI FEG Nova 600 Nanolab at $5 \mathrm{kV}$. Figure 7 shows the SEM image of 5\% Mn:ZnO film. Surface morphology study of 5\% Mn: $\mathrm{ZnO}$ films shows wrinkle structure with formation of nanorods in certain regions. Similar observation of appearance of wrinkle structure due to $\mathrm{Mn}$ incorporation has been reported by Nirmala and Anukaliani (2010). Srinivasan and Kumar (2008) were also reported microstructure consisting of nanorods with wrinkle structure for Mn-doped films.

The compositional analysis of Mn-doped $\mathrm{ZnO}$ film carried out by energy dispersive X-ray analysis is shown in figure 8. Figure 8(a) shows the EDX spectrum of $2 \%$ $\mathrm{Mn}: \mathrm{ZnO}$ and figure $8(\mathrm{~b})$ shows the spectrum of $5 \% \mathrm{Mn}: \mathrm{ZnO}$.

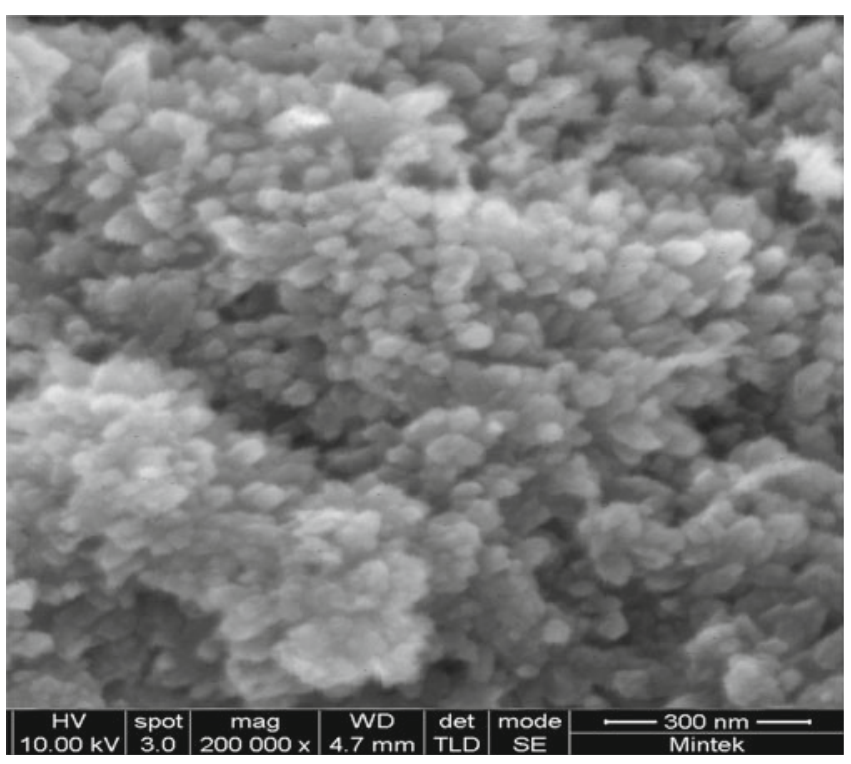

Figure 6. HRSEM image of $\mathrm{ZnO}$.

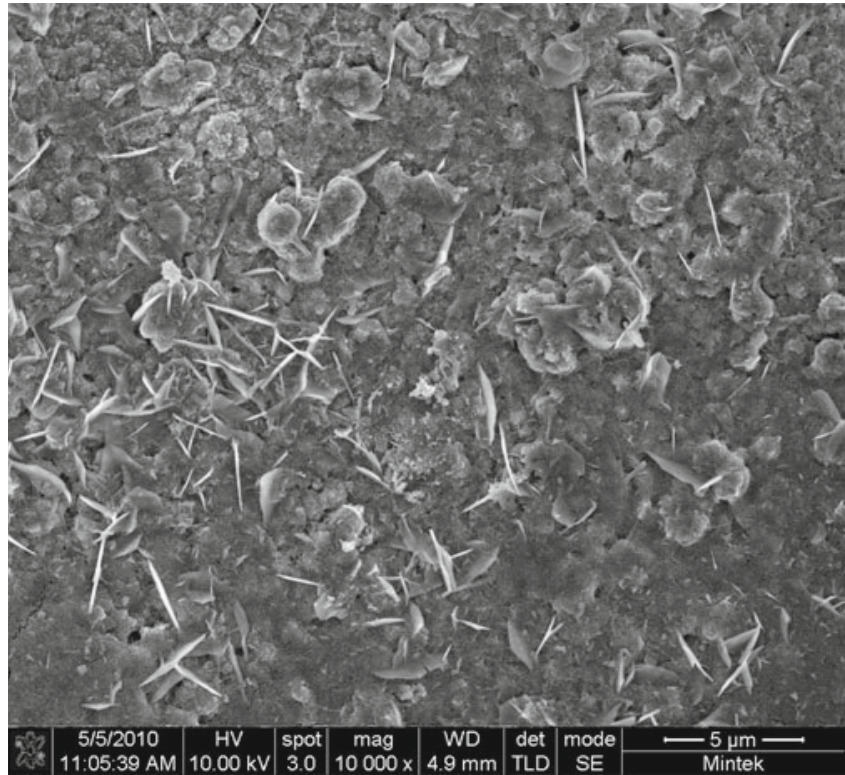

Figure 7. SEM image of $5 \% \mathrm{Mn}: \mathrm{ZnO}$ thin film.

The EDX spectrum confirmed the presence of $\mathrm{Zn}, \mathrm{O}$ and $\mathrm{Mn}$ elements in the deposited films. The silicon signal possibly appears from the substrate. Dopant concentration in these two cases was 2 and 5\% in the starting solution. Accordingly, the expected $\mathrm{Mn} / \mathrm{Zn}$ ratio was 0.02 and 0.05 in the films. We actually obtained the $\mathrm{Mn} / \mathrm{Zn}$ ratio in the films as 0.0131 and 0.0284 , respectively, indicating that the amount of $\mathrm{Mn}$ incorporation in the film is less than the amount of $\mathrm{Mn}$ in the starting solution. The real Mn content in the deposited films was 1.31 and $2.84 \%$ as obtained from EDX spectrum. EDX investigations on glass and quartz substrate with increasing Mn content in the starting solution are underway.

\subsection{Optical absorption}

The optical absorbance spectrum was recorded in the wavelength range of $500-800 \mathrm{~nm}$ using a Shimadzu spectrophotometer-1800. Zinc oxide is a direct bandgap material (Tabet-Derraz et al 2002) and the energy gap $\left(E_{\mathrm{g}}\right)$ can thus be estimated by assuming direct transition between conduction bands and valence bands. Theory of optical absorption gives the relationship between the absorption coefficients, $\alpha$ and the photon energy, $h v$ as

$$
\alpha h v=A\left(h v-E_{\mathrm{g}}\right)^{n / 2},
$$

where $A$ is a function of index of refraction and hole/electron effective masses (Pankove 1971), $\alpha$ the optical absorbance and ' $n$ ' a number equal to 4 for direct bandgap and 1 for the indirect bandgap semiconductors.

For our present case $n=4$, the direct bandgap is determined using this equation, when straight portion of the $(\alpha h \nu)^{2}$ against $h v$ plot is extrapolated to intersect the energy axis at $\alpha=0$. Figure 9 shows the dependence of optical 


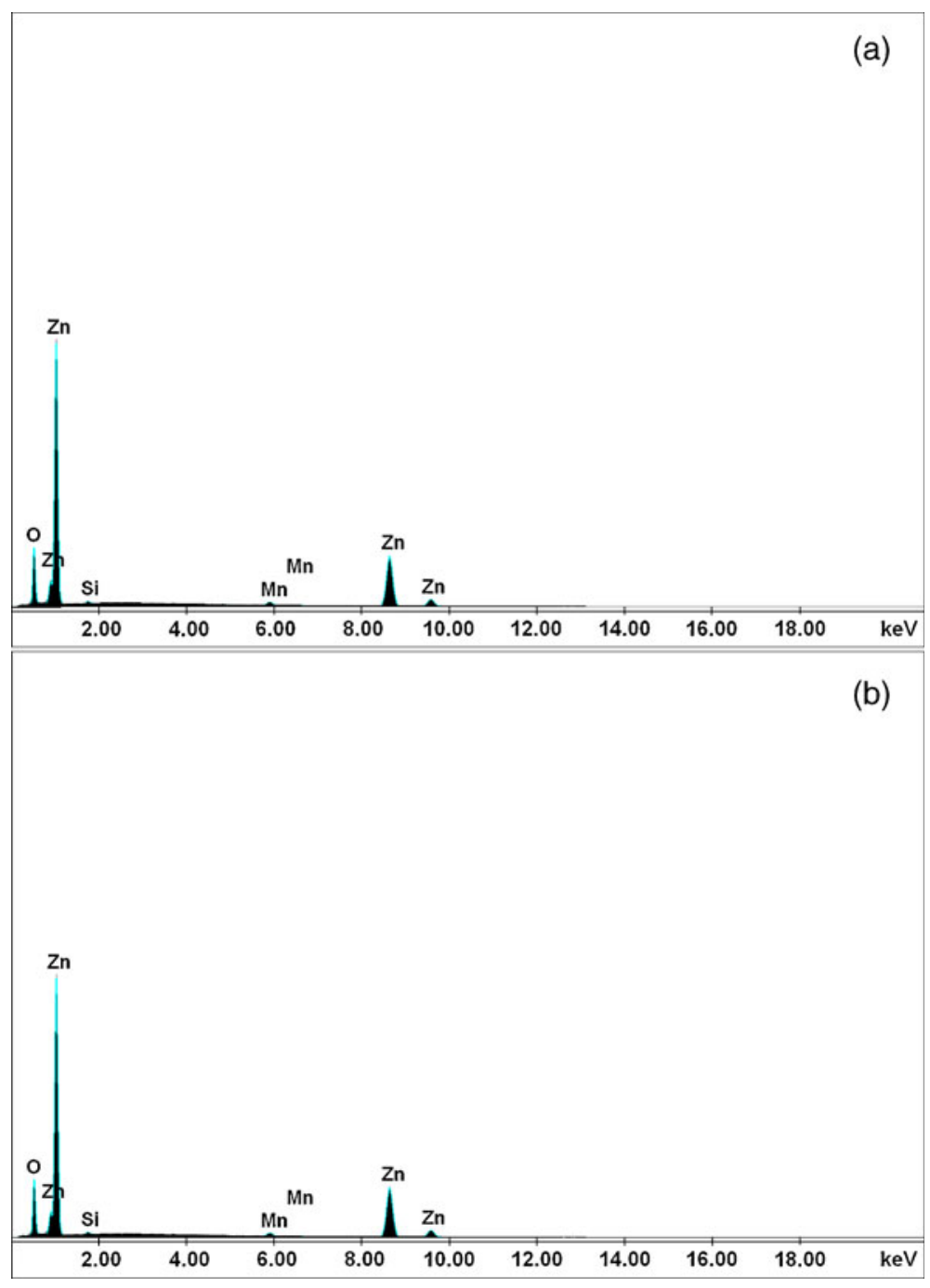

Figure 8. EDX pattern of (a) $2 \% \mathrm{Mn}: \mathrm{ZnO}$ and (b) $5 \% \mathrm{Mn}: \mathrm{ZnO}$.

absorbance $(\alpha)$ on wavelength $(\lambda)$. While figure 9(a) shows the dependence of $\alpha$ on $\lambda$ for pure $\mathrm{ZnO}$, figures 9(b) and (c) show dependence of $\alpha$ on $\lambda$ for $2 \% \mathrm{Mn}: \mathrm{ZnO}$ and $5 \%$ $\mathrm{Mn}: \mathrm{ZnO}$, respectively. Plot of $(\alpha h v)^{2}$ against $h v$ for undoped and $\mathrm{Mn}$-doped $\mathrm{ZnO}$ films was derived from figure 9 and is shown in figure 10. Figure 10(a) shows the spectrum of pure $\mathrm{ZnO}$ while figures 10 (b) and (c) show the spectrum of $2 \%$ $\mathrm{Mn}: \mathrm{ZnO}$ and 5\% $\mathrm{Mn}: \mathrm{ZnO}$, respectively.

It is seen that with the increase of manganese doping level, the fundamental absorption edge decreases. The value of $E_{\mathrm{g}}$ for undoped $\mathrm{ZnO}$ is $3.22 \mathrm{eV}$. It decreases to $3.13 \mathrm{eV}$ for $2 \% \mathrm{Mn}: \mathrm{ZnO}$ and $3.06 \mathrm{eV}$ for $5 \% \mathrm{Mn}: \mathrm{ZnO}$. The decrease in bandgap value with increased Mn doping concentration has been accounted due to the $s p$ - $d$ exchange interactions and has been theoretically explained using the second-order perturbation theory (Bylsma et al 1986; Singh et al 2009; Nirmala and Anukaliani 2010). A decrease in bandgap energy from $3.27 \mathrm{eV}$ for undoped $\mathrm{ZnO}$ to $2.78 \mathrm{eV}$ for $3 \%$ Mn-doped $\mathrm{ZnO}$ has been reported by Senthilkumar et al

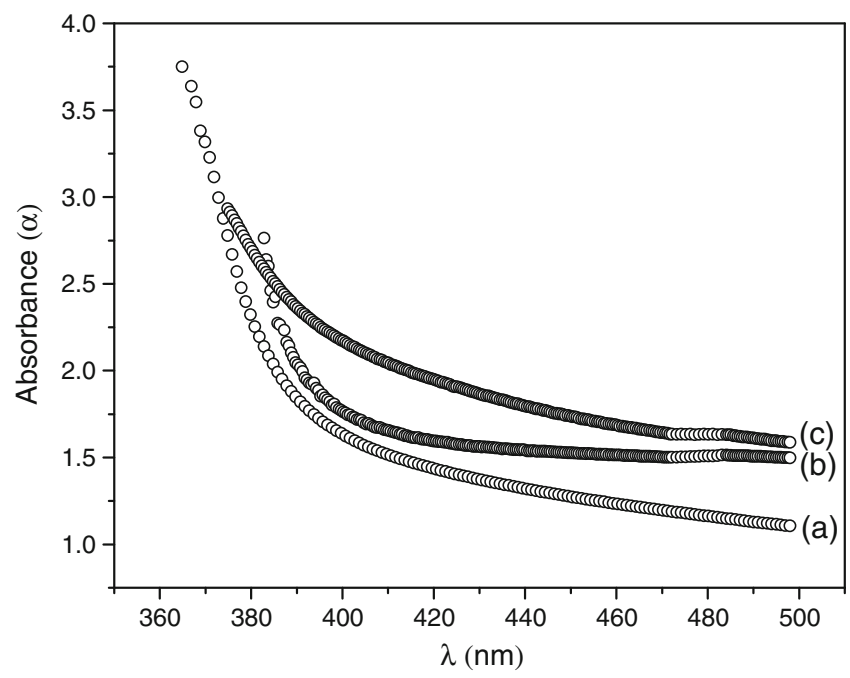

Figure 9. Plot of absorbance vs wavelength: (a) pure $\mathrm{ZnO}$; (b) $2 \% \mathrm{Mn}: \mathrm{ZnO}$ and (c) $5 \% \mathrm{Mn}: \mathrm{ZnO}$. 


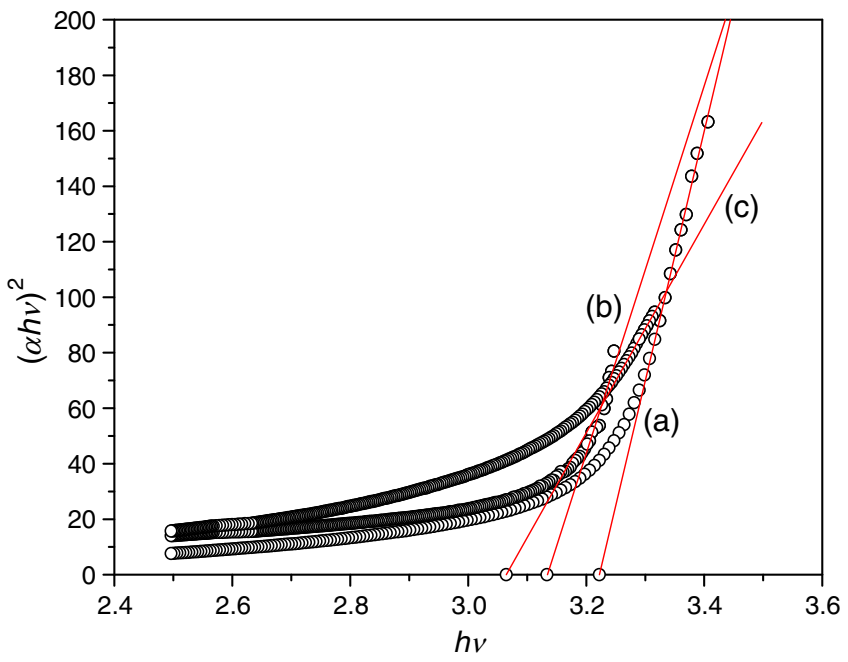

Figure 10. Plot of $(\alpha h v)^{2}$ vs $h v$ (in eV) for (a) pure $\mathrm{ZnO}$; (b) $2 \%$ $\mathrm{Mn}: \mathrm{ZnO}$ and (c) $5 \% \mathrm{Mn}: \mathrm{ZnO}$.

(2008) and has been attributed to $s$ - $d$ and $p$ - $d$ interactions giving rise to bandgap bowing.

\section{Conclusions}

The primary aim of the present investigation was to explore the possibility of doping $\mathrm{ZnO}$ with manganese by SILAR method. Mn-doped $\mathrm{ZnO}$ films with different percentage of Mn content ( 2 and 5\%) could be successfully synthesized through this technique for the first time. The films had good adherence to the substrate. Apart from being an inexpensive and simple technique, the method uses milder reaction conditions than those employed by most chemical methods proposed in the literature. Particle size is evaluated, using X-ray line broadening analysis and Williamson-Hall method shows a constantly decreasing trend with increasing manganese incorporation. The average particle size of $29.71 \mathrm{~nm}$ evaluated by X-ray line broadening method matches well with SEM observation. The average particle size reduces to $26.69 \mathrm{~nm}$ for $2 \% \mathrm{Mn}: \mathrm{ZnO}$ and $23.76 \mathrm{~nm}$ for $5 \% \mathrm{Mn}: \mathrm{ZnO}$. The films are polycrystalline with an average porosity of $\sim 22 \%$. The polycrystallinity of the films as well as the average microstrain increase with increasing Mn incorporation. These observations along with EDX observation confirms the replacement of zinc ions by manganese ions in the $\mathrm{ZnO}$ lattice. The real $\mathrm{Mn}$ content in the deposited film was less than that in the starting solution. Mn doping reduces fundamental absorption edge. It decreases to $3.06 \mathrm{eV}$ for $5 \% \mathrm{Mn}: \mathrm{ZnO}$ and to $3.22 \mathrm{eV}$ for pure $\mathrm{ZnO}$. The materials are therefore useful for configurations that involve bandgap engineering.

\section{Acknowledgements}

One of the authors (PM) would like to acknowledge CSIR (Council of Scientific and Industrial research, New Delhi, India) for supporting the work in the form of a research project [No. 03 (1195)/11/EMR-II].

\section{References}

Bylsma R B, Becker W M, Kossut J, Debska U and Short D Y 1986 Phys. Rev. B33 8207

Choudhury N and Sarma B K 2009 Bull. Mater. Sci. 3243

Deka S and Roy P A 2007 Solid State Commun. 142190

Ghosh B, Dutta H and Pradhan S K 2009 J. Alloys Compd. 479193

Jumin X and Wang J 2001 Mater. Lett. 49318

Kale S S, Mane R S, Pathan H M, Shaikh A V, Joo O S and Han S H 2007 Appl. Surf. Sci. 2534335

Keis K, Bauer C and Boschloo G 2002 J. Photochem. Photobiol. A148 57

Klug H P and Alexander L E 1974 X-ray diffraction procedures for polycrystalline and amorphous materials (New York: Wiley)

Kundaliya D C et al 2004 Nature Mater. 3709

Look D C 2001 Mater. Sci. Eng. 80383

Luo J, Liang J K, Liu Q L, Liu F S, Zhang Y, Sun B J and Rao G H 2005 J. Appl. Phys. 97086106

Maiti U N, Ghosh P K, Ahmed F, Mitra M K and Chattopadhyay K K 2007 J. Sol-Gel Sci. Technol. 4187

Mandal S K and Nath T K 2006 Thin Solid Films 5152535

Mitra P and Khan J 2006 Mater. Chem. Phys. 98279

Mondal S, Kanta K P and Mitra P 2008 J. Phys. Sci. 12221

Mondal S and Mitra P 2012 Bull. Mater. Sci. 35751

Natsume Y 2000 Thin Solid Films 37230

Negami T, Hashimoto Y and Nishiwaki S 2001 Sol. Energy Mater. Sol. Cells 67331

Nirmala M and Anukaliani A 2010 Photonics Letters of Poland 2 189

Pankove J I 1971 Optical processes in semiconductors (Englewood Cliffs, NJ: Prentice-Hall)

Patra S, Mitra P and Pradhan S K 2011 Mater. Res. (ISSN: 15161439) 1417

Senthilkumar S, Rajendran K, Banerjee S, Chini T K and Sengodan V 2008 Mater. Sci. Semicond. Proc. 16

Sharma P et al 2003 Nature Mater. 2673

Singh P, Kaushal A and Kaur D 2009 J. Alloys Compd. 47111

Singhal R K, Dhawan M, Kumar S, Dolia S N, Xing Y T and Saitovitch E 2009 Physica B404 3275

Srinivasan G and Kumar J 2008 Appl. Surf. Sci. 2547285

Tabet-Derraz H, Benramdane N, Nacer D, Bouzidi A and Medles M 2002 Sol. Energy Mater. Solar Cells 73249

Ungar T and Borbely A 1996 Appl. Phys. Lett. 693173

Wang X, Careg W P and Yee S 1995 Sens. Actuator. B28 63 